\title{
Isolation and identification of anaerobic organisms from the male and female urogenital tracts
}

\author{
SHEILA MOSS \\ From the Department of Medical Microbiology, Sheffield University Medical School, Sheffield
}

SUMMARY Since Bacteroides spp may play an important role together with Gardnerella $\stackrel{\vec{\omega}}{\vec{\omega}}$ vaginalis in the pathogenesis of non-specific vaginitis and balanoposthitis, anaerobic organisms $\stackrel{\sigma}{\sigma}$ were isolated and identified from 34 female and 20 male patients attending a department of $\stackrel{\infty}{=}$. genitourinary medicine, and the results compared with the clinical findings and the presence of 0 other routinely isolated pathogens. Twenty-three different organisms were recovered from 13 of $\omega$ the 20 men; of these organisms, 20 were of the Bacteroides spp. Most isolates were of the $B$ 営 melaninogenicus/oralis group, which forms part of the commensal vaginal flora in women.

A definite association between the presence of anaerobes and other pathogens needs to be firmly established, as this obviously causes important complications in treating these conditions.

\section{Introduction}

Very little is known about the normal commensal flora of the male urethra or of the way it may be modified by the presence of pathogenic organisms.

The Gram negative anaerobic bacilli that form part of the commensal flora of the female genital tract have been well documented by Duerden. ${ }^{1}$ Bacteroides spp were isolated from the cervix and posterior fornix of the vagina in $65 \%$ of women, the most common species found being of the $B$ melaninogenicus/oralis group. The study group consisted of normal healthy women attending a family planning clinic; women with vaginal pathology were not included.

In a study by Hafiz et al of the Gram positive anaerobic bacillus, Clostridium difficile, in the urogenital tract of men and women higher isolation rates of this organism were found in patients attending a department of genitourinary medicine than in control groups attending family planning or urology clinics. Hall and O'Toole ${ }^{3}$ first isolated strains of $\mathrm{Cl}$ difficile from meconium and faeces of infants, which suggested that material from the adult vagina should be examined for these organisms. When vaginal specimens from women attending a department of genitourinary medicine were compared with those from a group attending a family

Address for reprints: Miss S Moss, Department of Medical Microbiology, Sheffield University Medical School, Beech Hill Road, Sheffield S10 2RX

Accepted for publication 29 November 1982 planning clinic $\mathrm{Cl}$ difficile was identified in $71 \%$ and $\vec{\oplus}$ $18 \%$ respectively. ${ }^{2} \mathrm{Cl}$ difficile was isolated from $\omega$ urethral swabs from all the men with non-specific $\square$ urethritis, but no positive cultures were obtained from men attending the urology clinic. Thus, $\mathrm{Cl}$ 응 difficile seemed to be an opportunist, infecting the urogenital tract already damaged by a recognised pathogen, or it might have been the primary $\overrightarrow{\vec{P}}$ pathogen in cases of non-specific urethritis.

The causative organisms of non-specific vaginitis (NSV) and urethritis (NSU) are open to controversy. Gardnerella vaginalis was isolated from $8 \%$ of women attending a family planning clinic, and of these $17 \%$ had positive cultures for $\mathrm{Cl}$ difficile from 3 high vaginal specimens. ${ }^{4}$ In the presence of $G_{\text {. }}$ vaginalis abnormalities of vaginal dischargeparticularly an offensive odour-were common. The culture rates $(6 \%)$ of $G$ vaginalis in this study differed appreciably from those of McCormack et $\$$ $a l,{ }^{5}$ who isolated the organism from $32 \%$ of vaginal swabs from female undergraduates and of Rodgers $e t \tilde{N}$ $a l$, who found an isolation rate of $60 \%$ in women attending a sexually transmitted disease clinic. ${ }^{6}$

Spiegel $e t a \bar{l}$ assessed the role of anaerobic $\omega$ bacteria in NSV. Previous studies had found increased numbers of $G$ vaginalis and an increased concentration of anaerobic bacteria in the vaginal $\mathbb{\Phi}$ fluid of women with NSV. The efficacy of ${ }^{\circ}$ metronidazole in the treatment of this condition also ${ }^{\circ}$ suggests that anaerobes may have an important role $\frac{\mathrm{C}}{\mathbb{D}}$

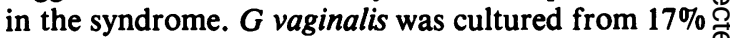
of the women with NSV and Bacteroides spp from $\varnothing$ $19 \%$. Again, most isolates of Bacteroides spp were of 
the $B$ melaninogenicus/oralis group, as were most isolates found in normal healthy women.

The present study was undertaken to determine the carriage rate of bacteroides and clostridia in the urogenital tract of men and women attending the department of genitourinary medicine in Sheffield, to identify the strains isolated, and to correlate these findings with the patients' symptoms, clinical signs, and the presence of other routinely isolated pathogens.

\section{Patients and methods}

\section{COLLECTION OF SPECIMENS}

Cervical swabs were collected from 34 women attending the department of genitourinary medicine, Sheffield, under direct vision during examination with a Cusco's speculum and before bimanual examination. The swabs were broken off immediately into Amies' transport medium with charcoal. Specimens were not included from women receiving antibiotic treatment. Urethral swabs were collected from 20 men and transported as above. Samples were processed on the same day that they were collected.

The anaerobic procedure of Collee $e t a{ }^{\beta}$ was followed; specimens were incubated at $37^{\circ} \mathrm{C}$ in an atmosphere of $90 \% \mathrm{H}_{2}$ and $10 \% \mathrm{CO}_{2}$.

\section{ISOLATION OF BACTEROIDES}

Each swab was used to seed a plate of prereduced BM agar which had been made selective for Bacteroides spp by the addition of kanamycin 75 $\mu \mathrm{g} / \mathrm{ml}$ and vancomycin $2.5 \mu \mathrm{g} / \mathrm{ml} .{ }^{9}$ After incubation for at least 48 hours the plates were examined; smears of representative colonies were Gram stained and appropriate individual colonies subcultured on to BM agar with a metronidazole disc. An aerobic control plate of the particular colony type was also set up.

\section{ISOLATION OF CLOSTRIDIA}

Each swab was used to seed three plates: blood agar; reinforced clostridial agar, and CCFA, a selective media for $\mathrm{Cl}$ difficile. ${ }^{10}$ After incubation for $\mathbf{4 8}$ hours the plates were examined and smears from isolated colonies Gram stained. Each appropriate colony was subcultured on to a blood agar plate for anaerobic incubation and for aerobic control cultures.

After the four plates had been seeded the swab was placed in a universal container filled with RCM broth plus $0.2 \%$ paracresol as a selective medium for $\mathrm{Cl}$ difficile. ${ }^{11}$ These were incubated anaerobically at $37^{\circ} \mathrm{C}$ and examined for evidence of growth. The broths were subcultured on to selective media after several weeks.

\section{IDENTIFICATION OF ISOLATES}

The strains of Bacteroides were identified by the methods of Duerden. ${ }^{9}$ This included colonial and cell morphology, pigment production, haemolysis, antibiotic disc resistance tests with discs containing neomycin $1000 \mu \mathrm{g}$, kanamycin $1000 \mu \mathrm{g}$, penicillin 2 units, and rifampicin $15 \mu \mathrm{g}$, tolerance tests with taurocholate, deoxycholate, Victoria blue $4 R$, and ethyl violet, biochemical tests for the production of indole, digestion of gelatin, and hydrolysis of aesculin, and fermentation tests with glucose, lactose, sucrose, rhamnose, trehalose, mannitol, and xylose.

The strains of clostridia were identified on the basis of colonial and cell morphology, fermentation of glucose, maltose, lactose, sucrose, salicin, and mannitol, gelatin digestion, and neutralisation of lecithinase by appropriate antitoxin. ${ }^{12}$ The identity of the strains was confirmed by gas-liquid chromatographic analysis.

\section{Results}

Fifty-four specimens were examined, from which 48 strains of clostridia or bacteroides were isolated for further study; 23 of these strains were isolated from 20 urethral swabs from men and 25 from 34 cervical specimens from women.

\section{WOMEN}

Anaerobes were isolated from $50 \%$ of the female patients. The isolation rate for symptomatic and asymptomatic women was $61 \%$ and $27 \%$ respectively. Overall isolation rate of $G$ vaginalis was $41 \%-48 \%$ from symptomatic and $27 \%$ from asymptomatic women. Both organisms were found in $26 \%$ of patients, $35 \%$ in symptomatic and $9 \%$ in asymptomatic women (table I).

Twelve women had a diagnosis of NSV; of these chlamydiae were isolated from $50 \%$ and anaerobes

TABLE I Isolation of anaerobes and $G$ vaginalis from patients attending a genitourinary medicine clinic

\begin{tabular}{|c|c|c|c|}
\hline \multirow[b]{2}{*}{$\begin{array}{l}\text { Organisms } \\
\text { isolated }\end{array}$} & \multicolumn{3}{|c|}{ No of patients: } \\
\hline & $\begin{array}{l}\text { With } \\
\text { symptoms* }\end{array}$ & $\begin{array}{l}\text { Without } \\
\text { symptomst }\end{array}$ & Total No \\
\hline \multicolumn{4}{|l|}{ Women: } \\
\hline $\begin{array}{l}\text { Anaerobes } \\
G \text { vaginalis } \\
\text { Anaerobes and }\end{array}$ & $\begin{array}{l}14 \\
11\end{array}$ & $\begin{array}{l}3 \\
3\end{array}$ & $\begin{array}{l}17 \\
14\end{array}$ \\
\hline$G$ vaginalis & 8 & 1 & 9 \\
\hline $\begin{array}{l}\text { Men: } \\
\text { Anaerobes }\end{array}$ & 8 & 5 & 13 \\
\hline
\end{tabular}

*23 women and 15 men +11 women and 5 men 
also from $50 \%$ (table II). Both chlamydiae and anaerobes were isolated from $25 \%$ of these women. $G$ vaginalis was isolated from $42 \%$ of the women with NSV and $G$ vaginalis and anaerobes from $25 \%$.

Of 25 species of anaerobes isolated from 17 specimens, 24 were isolates of Bacteroides spp (table III). $B$ fragilis does not usually form part of the normal vaginal flora. Three women had $B$ fragilis isolated; two of these women had symptoms and two harboured $B$ oralis and $G$ vaginalis.

A total of 21 species of anaerobes were isolated from 23 symptomatic women and four species from 11 asymptomatic women (table IV). Among the symptomatic women, 14 isolates were of the $B$ melaninogenicus/oralis group, two were $B$ fragilis, and five $B$ asaccharolyticus. In the asymptomatic group there were two isolates of the $B$ melaninogenicus/oralis group, one isolate of $B$ fragilis, and one of $\mathrm{Cl}$ perfringens.

TABLE II Isolation of chlamydiae, $G$ vaginalis, and anaerobes from patients with NSV

\begin{tabular}{ll}
\hline Organism isolated & No of women with NSV \\
\hline Chlamydiae & 6 \\
Anaerobes & 6 \\
$G$ vaginalis & 5 \\
$G$ vaginalis and anaerobes & 3 \\
Chlamydiae and anaerobes & 3 \\
\hline
\end{tabular}

TABLE III Species of Bacteroides isolated

\begin{tabular}{ll}
\hline & No isolated \\
\hline Bacteroides spp & 24 \\
$B$ melaninogenicus/oralis & 16 \\
$B$ asaccharolyticus & 5 \\
$B$ fragilis* & 3 \\
\hline
\end{tabular}

*One also had an isolate of $\mathrm{Cl}$ perfringens

TABLE IV Relation between species isolated and presence of symptoms in women

\begin{tabular}{lll}
\hline Organism isolated & $\begin{array}{l}\text { No (\%) of } \\
\text { symptomatic } \\
\text { women }\end{array}$ & $\begin{array}{l}\text { No (\%) of } \\
\text { asymptomatic } \\
\text { women }\end{array}$ \\
\hline B melaninogenicus/ & $14(67)$ & $2(50)$ \\
$\begin{array}{l}\text { oralis } \\
\text { B fragilis }\end{array}$ & $2(9 \cdot 5)$ & $1(25)$ \\
$C l$ perfringens & $5(25)$ & $1(25)$ \\
\hline
\end{tabular}

MEN

The overall isolation rate of anaerobes from the male patients was $65 \%$ (table I). Anaerobes were isolated from $53 \%$ of symptomatic and from $100 \%$ of asymptomatic men. Many of these men had more than one species isolated.
A total of 14 had a diagnosis of NSU. Nine of $\stackrel{\Phi}{\overparen{D}}$ these men had anaerobic organisms isolated, four $\square$ also had $N$ gonorrhoeae. Fourteen isolates of Bacteroides spp were recovered from these men, $\overrightarrow{\bar{F}}$ most $(9 / 14)$ being of the $B$ melaninogenicus/oralis group (table V). There were also two isolates of clostridia from these men.

Six isolates of Bacteroides spp were recovered from the six men who did not have a diagnosis of NSU. Three of these isolates were of the $B$ i melaninogenicus/oralis group. There was one isolate $\vec{\circ}$ of $\mathrm{Cl}$ sporogenes from this group of men.

TABLE V Relation between species of anaerobes isolated and diagnosis of NSU in men

\begin{tabular}{|c|c|c|c|}
\hline Organism isolated & $\begin{array}{l}\text { No of men } \\
\text { with NSU }\end{array}$ & $\begin{array}{l}\text { No of men } \\
\text { without NSU }\end{array}$ & Total \\
\hline $\begin{array}{l}\text { Bacteroides } \\
\text { melaninogenicus/oralis } \\
\text { fragilis } \\
\text { asaccharolyticus } \\
\text { corrodens } \\
\text { fusobacterium } \\
\text { necrogenes }\end{array}$ & $\begin{array}{l}9 \\
2 \\
2 \\
1\end{array}$ & $\begin{array}{l}3 \\
2\end{array}$ & $\begin{array}{r}12 \\
4 \\
2 \\
1 \\
1\end{array}$ \\
\hline $\begin{array}{l}\text { Clostridia } \\
\text { tetanomorphum } \\
\text { sporogenes }\end{array}$ & $\begin{array}{l}1 \\
1\end{array}$ & 1 & $\begin{array}{l}1 \\
2\end{array}$ \\
\hline
\end{tabular}

These studies have confirmed that a range of $\stackrel{\mathbb{Q}}{\complement}$ anaerobic bacteria can be isolated from the female $\overrightarrow{\vec{O}}$ genital tract and also from the male urethra.

Duerden $^{1}$ isolated Bacteroides spp from $65 \%$ of $\supset$ asymptomatic women attending a family planning? clinic. In the present study Bacteroides spp were isolated from only three of 11 asymptomatic women-that is, $<30 \%$. This discrepancy may be due $\exists$ to the relatively small sample, especially when a large variation in the number of anaerobic organisms isolated is dependent on the phase in the menstrual cycle. Moreover, sampling techniques were different; only samples from the external os were taken in this study. There may also have been some inherent differences between the two study populations.

Anaerobic organisms were isolated from 14 of the 23 symptomatic women. $G$ vaginalis was isolated from about $50 \%$ of the symptomatic women but only from about $25 \%$ of those without symptoms. These figures compare favourably with those of McCormack et $a l^{5}$ and Rodgers et alt.

Symptomatic women also had a considerably? higher isolation rate of both $G$ vaginalis and anaerobes (about 30\%) than those women without $\frac{}{\circ}$ symptoms $(9 \%)$.

Among the 12 women who had a diagnosis of $\stackrel{\mathbb{D}}{\circ}$ NSV, anaerobes were isolated from $50 \%$ and $G$ ? 
vaginalis from $42 \%$. Anaerobes together with $G$ vaginalis were present in $25 \%$ of these women; a further $25 \%$ had anaerobes and Chlamydia trachomatis isolated. Most isolates of Bacteroides spp were of the $B$ melaninogenicus/oralis and $B$ asaccharolytic groups which comprise most of the normal vaginal flora. When $B$ fragilis was found, however, the incidence of associated symptoms or other pathogens was no higher. This generally supports the findings of Spiegel et al, ${ }^{7}$ who reported a greater prevalence of anaerobes and $G$ vaginalis in women with NSV.

In men anaerobic organisms were isolated from eight of 15 symptomatic and from all five asymptomatic patients. A total of 14 men had a diagnosis of NSU; anaerobes were isolated from nine of these. The species of anaerobes found was similar to those in the women. A total of 16 anaerobic isolates were obtained from 14 men with NSU and seven isolates from six men without.

With this sample size it is not possible to make any clear distinction between these two groups; however, when symptoms are taken into account anaerobes were isolated from only slightly more than $50 \%$ of symptomatic men whereas they were present in all the asymptomatic men. This might suggest that the presence of symptoms is associated with a disturbance of the normal anaerobic flora. Whether or not this is the case, it appears that anaerobes occur commonly in the male urethra in many circumstances, both with and without either other sexually transmitted pathogens or symptoms. Their specific role either as a commensal or copathogen requires further investigation.

Though several species of Gram positive anaerobic bacilli were isolated from both the male and female patients, $\mathrm{Cl}$ difficile was not isolated. The criteria for identification used by Hafiz et al were insufficiently precise. Organisms which formed a characteristic pattern in RCM broth with paracresol were found to be diphtheroids in Gram stained smears and others grew aerobically on media selective for enteric organisms. These organisms did not grow on the specific isolation medium (CCFA) used for $\mathrm{Cl}$ difficile.

I thank Difco Laboratories for their financial support, Dr B I Duerden for his supervision and encouragement, and $\operatorname{Dr} G R$ Kinghorn for his cooperation in collecting the specimens. I also thank Julia Faulkner for her technical advice and Hazel Bland for typing this report.

\section{References}

1. Duerden, BI. The isolation and identification of Bacteroides spp from the normal human vaginal flora. J Med Microbiol 1980;13:79.

2. Hafiz S, McEntegart MG, Morton RS, Waitkins SA. Cl difficile in the urogenital tract of males and females. Lancet 1975 ; i: 420.

3. Hall IC, O'Toole $E$. Intestinal flora in newborn infants, with description of new pathogenic anaerobe bacillus difficilis. $\mathbf{A m}$ $J$ Dis Child 1935; 49:390.

4. Bramley HM, Dixon RA, Jones BM. Haemophilus vaginalis (C vaginale, $G$ vaginalis) in a family planning clinic population. $B r$ $J$ Vener Dis 1981;57:62.

5. McCormack WM, Hayes CM, Rosner BI. Vaginal colonization with $C$ vaginale (H vaginalis). J Am Vener Dis Assoc 1976; 3:9.

6. Rodgers HA, Hesse FA, Pulley HC, Hines PA, Smith RF, $H$ vaginalis vaginitis in females attending public health clinics, response to ampicillin. Sex Transm Dis 1978;5:18.

7. Spiegel CA, Amsel R, Eschenbach DE, Schoenecht F, Holmes $\mathrm{KK}$. Anaerobic bacteria in non-specific vaginitis. $N$ Engl J Med 1980; 303:601.

8. Collee JG, Watt B, Fowler EB, Brown RA. An evaluation of the Gaspak system in the culture of anaerobic bacteria. J App Bacteriol 1972;35:71.

9. Duerden BI. The identification of Gram-negative anaerobic bacilli isolated from clinical infections. J Hyg Camb 1979;84:301.

10. George WL, Sutter VL, Citron D, Finegold SM. Selective and differential medium for the isolation of $\mathrm{Cl}$ difficile. $\mathrm{J}$ Clin Microbiol 1979; 9:214.

11. Hafiz S, Oakley CL. Cl difficile isolation and characteristics. $J$ Med Microbiol 1976; 9: 129.

12. Willis AT. Anaerobic bacteriology. Clinical and laboratory practice, 3rd ed. London: Butterworths, 1977. 